American Journal of Environmental Sciences 5 (3): 310-314, 2009

ISSN $1553-345 \mathrm{X}$

(C) 2009 Science Publications

\title{
Electroosmotic Phenomena in Organic Soils
}

\author{
${ }^{1}$ Afshin Asadi, ${ }^{1}$ Bujang B.K. Huat, ${ }^{1}$ M.M. Hassim, ${ }^{1}$ Thamer A. Mohamed, \\ ${ }^{2}$ M.M. Hanafi and ${ }^{3}$ Nader Shariatmadari \\ ${ }^{1}$ Department of Civil Engineering, \\ University Putra Malaysia, 43400 UPM Serdang, Selangor, Malaysia \\ ${ }^{2}$ Institute of Tropical Agriculture, \\ University Putra Malaysia, 43400 UPM Serdang, Selangor, Malaysia \\ ${ }^{3}$ College of Civil Engineering, Iran University of Science and Technology, Tehran, Iran
}

\begin{abstract}
Organic soils or peat represent an accumulation of disintegrated plant remains which have been preserved under condition of incomplete aeration and high water content. In order to develop a fundamental understanding of electroosmotic phenomena in peat, initially microelectrophoresis studies were carried out to conceptualize the electrokinetic phenomena. Then electroosmosis experiments were conducted on rigid cube samples containing $0.0001 \mathrm{M} \mathrm{NaCl}$-water saturated peat. The openanode and open-cathode systems were employed to the soil samples. Distilled Water (DW) were used as anolyte and catholyte. The experiments were carried out via applications of diffrent DC electrical potentials. The results of microelectrophoresis study showed changes of zeta potential due to the effect of $\mathrm{HCl}$ and $\mathrm{NaOH}$. The correlations between zeta potential and $\mathrm{pH}$ were found. The negative charge of peat is high $\mathrm{pH}$ dependent and the surface charge was dropped to zero at $\mathrm{pH}$ around 3 . The high degree of decomposition resulted in the higher zeta potential in peat. It was also experimentally found that the electroosmotic flow in peat is feasible. The direction of electroosmotic flows were from the anode to cathode.
\end{abstract}

Key words: Electroosmotic flow, humification, organic content, zeta potential

\section{INTRODUCTION}

In 1809, Reuss, a researcher from Russia, was the first to observe water flow in soils as a result of a direct electric current passing through it. Electroosmosis (EO) is one of the electrokinetic phenomena where the pore fluid moves due to application of DC current (or voltage) by electrodes in a soil mass ${ }^{[1]}$.

Geotechnical and environmental engineers have been interested in electroosmosis for many years as a method of soil improvement including electroosmotic dewatering, ion injection, contaminant removal, electrobioremediation and electrochemical remediation ${ }^{[2]}$.

Soils with organic content of greater than $20 \%$ are generally termed organic soil. Peat is described as a naturally occurring highly organic substance derived primarily from plant materials. The definition of peat overtime and to different people has differed, although essentially all are agreed that it is primarily an organic soil $^{[3]}$. In Malaysia about $8 \%$ of the country's land area is covered with peat and generally termed basin and valley peat ${ }^{[3,4]}$. Peat and organic soils are extremely soft. These soils are geotechnically problematic due to their very high compressibility and very low shear strength ${ }^{[3,5]}$.

According to colloidal theory, a soil particle, when suspended in water, has a negatively charged surface. Surrounding the particle is double layer of positive ions. Most rigidly attached to the surface is the first layer of positive ions, with greater distance from the solid particle, the attractive force diminishes, giving rise to an increasingly diffuse ionic atmosphere (the second layer), where the ions are relatively free to move. The electroosmotic permeability is dependent on zeta potential, $\zeta$, which is defined as the electrical potential at the junction between the fixed and mobile parts of electrical double layer. Beyond the double layer, the ion concentration is equal to that of the free pore water. Because of the polar nature of water molecules they are oriented around cations. In the presence of water, the radius of an ion may thus increase to several times its original, nonhydrated

Corresponding Author: Bujang B.K. Huat, Department of Civil Engineering, Faculty of Engineering, University Putra Malaysia, 43400 UPM Serdang Selangor, Malaysia,

Tel: 603-89466368, Fax: 603-86567129 
dimension $^{[6]}$. Applying an electrical potential to the saturated soil causes the hydrated positive ions to move toward the negative electrode (the cathode), dragging free water with them. The movement is primarily generated in the diffuse double layer, also called soil moisture film, where the cations dominate. The higher the soil particle surface area, the more soil moisture film transfer will occur. Other important are the magnitude of the electrical potential applied and the viscosity of the pore fluid ${ }^{[7]}$.

The rate of water flow is controlled by the balance between the electrical force causing water movement in one direction and friction between the liquid and the wall in the other. The overall flow $\left(\mathrm{q}_{\mathrm{A}}\right)$ generated by the application of a potential difference (D) may be expressed as:

$\mathrm{q}_{\mathrm{A}}=\mathrm{k}_{\mathrm{e}}(\mathrm{V} / \mathrm{L}) \mathrm{A}$

Where:

$\mathrm{k}_{\mathrm{e}}=$ The electro osmotic permeability of the soil

$\mathrm{V} / \mathrm{L}=$ The electrical potential gradient

A $=$ The cross-sectional area of the soil sample across which the potential difference is applied

As such this is analogous to Darcy's Law of hydraulic flow. Where $\mathrm{Q}$ is the flow rate; $\mathrm{k}_{\mathrm{h}}$ is the hydraulic permeability; $i_{h}$ is the hydraulic gradient and $\mathrm{A}$ is the cross sectional area of the soil ${ }^{[7]}$ :

$$
\mathrm{Q}=\mathrm{k}_{\mathrm{h}} \mathrm{i}_{\mathrm{h}} \mathrm{A}
$$

The overriding benefit of electroosmosis is that $\mathrm{k}_{\mathrm{e}}$ is independent of pore size and has a relatively constant value in soils.

This study is devoted to describe a study on the zeta potential behaviour and the electroosmotic phenomena in organic soil and peat. To our knowledge, no research has been conducted on this subject. It is believed that study of electroosmosis phenomena in organic soils is crucial to extend its applications in geotechnical aspects.

\section{MATERIALS AND METHODS}

Peat: The peat samples were taken from $\mathrm{Kg}$. Jawa, Klang, Selangor, Malaysia. Loss of moisture from samples was prevented during transportation, preparation and storage (BS 1377-1: 1990). The sample for electroosmosis experiment was characterized physically and chemically, with results being shown in Table 1. Mineralogical analysis of the clay fraction showed the presence of kaolinite.
Table 1: Characteristics of the peat used in this study

\begin{tabular}{lrr}
\hline Variable & & Value \\
\hline Liquid limit (\%) & BS 1377-2:1990 & 280.0 \\
Specific gravity & BS 1377-2:1990 & 1.4 \\
Moisture content (\%) & BS 1377-2:1990 & 480.0 \\
Organic content (\%) & BS 1377-3:1990 & 83.0 \\
pH & BS 1377-3:1990 & 6.4 \\
Cation exchange capacity (meq/100 g) & & 86.0 \\
\hline
\end{tabular}

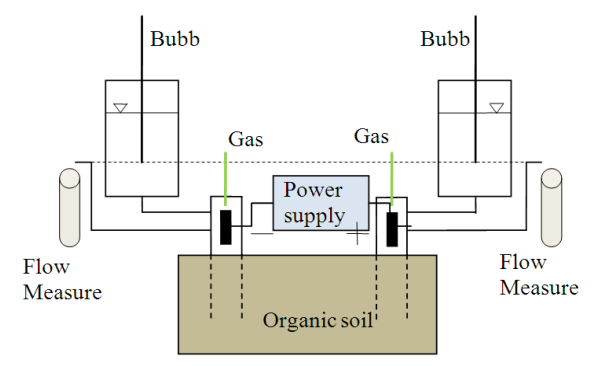

Fig. 1: Experimental set-up of the EK cell

Experimental setup: The EK cell consists of an acrylic cube measuring $10 \mathrm{~cm}$ in length, $5 \mathrm{~cm}$ in width and 5 $\mathrm{cm}$ in height Fig. 1. Two glass tubes, $1 \mathrm{~cm}$ in internal diameter with electrodes were pushed into the soil sample (the distance between two tubes was $6 \mathrm{~cm}$ ). The electrodes were made of graphite $\operatorname{rod}^{[8]}$. However, the electrodes were replaced at every test due to degradation. The electrodes have a pin that goes out of the glass tubes and are connected to the power supply. Each glass tube was connected to a bubble tube. The bubble tube maintained the water level across the specimen constant and therefore prevented development of any external hydraulic gradient across the specimen. The bubble tube was used to replenish water that may be lost in the electrode compartment due to any electroosmotic pore fluid flow. The opened anode and cathode systems were employed in this study.

Zeta potential of peat: Electrokinetics properties were determined by microelectrophoresis ${ }^{[9]}$. The peat samples with different organic content 48, 65 and 87\% were prepared by seiving through a seive size No. 100 $(150 \mu \mathrm{m})$. For each sample, a solution of $0.10 \mathrm{~g} \mathrm{~L}^{-1}$ of the pretreated soil in $0.0001 \mathrm{M} \mathrm{NaCl}$ was prepared. The samples were shaken overnight at room temperature before measurements. The zeta potential was measured with a zeta-meter (Zeta-meter System 3.0+ model) as a function of $\mathrm{pH}$ values ranging from 2-11. All measurements were made in $0.0001 \mathrm{M} \mathrm{NaCl}$ solutions and $\mathrm{pH}$ adjustments were made using dilute $\mathrm{NaOH}$ or $\mathrm{HCl}$ solutions. All solutions were made up with deionized water. 
Electroosmosis experiments: Initially, the peat specimens were compacted at $85 \%$ maximum (standard Proctor) dry density. Then the soil specimens were saturated in $0.0001 \mathrm{M} \mathrm{NaCl}$-water for 3 days. Distilled water was used as anolyte and catholyte in glass tubes. The measurments were carried out via applications of constant $50 \mathrm{~V}$ and $70 \mathrm{~V}$ DC electrical potential for $60 \mathrm{~min}$. The electroosmotic flow rate, final $\mathrm{pH}$ values at the anode, cathode and soil were measured. The tests were carried out in the laboratory in which the temperature was maintained constant to within $\pm 4^{\circ} \mathrm{C}$. All the tests were performed at least duplicate. If the test data for the duplicated samples were different more than $15 \%$, additional measurements were performed and the averages were taken from the test data.

\section{RESULTS AND DISCUSSION}

Zeta potential and $\mathbf{p H}$ : The zeta potential, $\zeta$, for the peat sample used in this study varied from $-39 \mathrm{mV}$ at $\mathrm{pH} 11.5$ to almost zero at $\mathrm{pH} 3$ (Fig. 2). Variations in $\zeta$ with $\mathrm{pH}$ is probably related to the nature of electrical energy field in organic soils, the negative charge of humus is generally believed to be due to the dissociation of $\mathrm{H}^{+}$from functional groups. All charge on humus is strongly $\mathrm{pH}$-dependent, humic acids behaving like polyprotonated weak acid. Many carboxylic groups are sufficiently acid to dissociate below $\mathrm{pH} 7$ leaving a negative charge on the functional group:

$$
\mathrm{R}-\mathrm{COOH}=\mathrm{R}-\mathrm{COO}^{-}+\mathrm{H}^{+}
$$

Here $\mathrm{R}$ represents any number of organic species whose differing electronegativities alter the tendency for $\mathrm{H}^{+}$to dissociate. Thus the various $\mathrm{R}-\mathrm{COOH}$ units dissociate at different $\mathrm{pH}$ values. As the $\mathrm{pH}$ of the system increases above 7 , still weaker carboxylic groups and other very weak acids dissociate ${ }^{[9,10]}$.

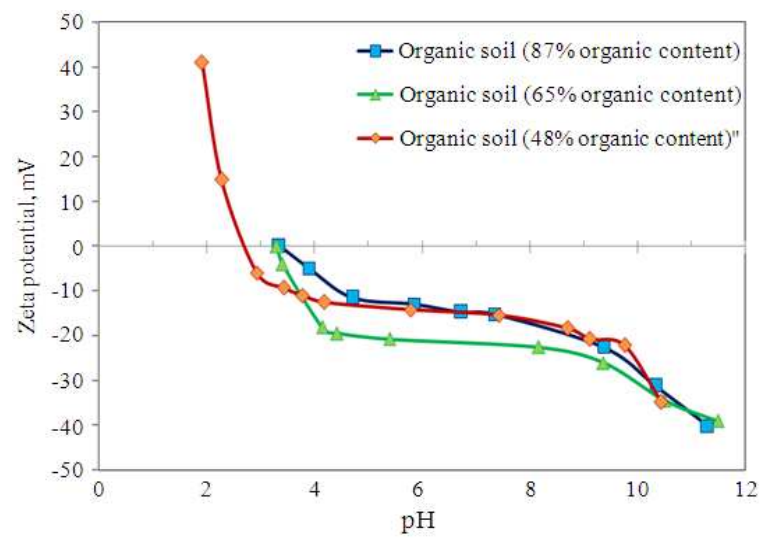

Fig. 2: Zeta potential-pH relationship
Protonated groups such as $\left(\mathrm{R}-\mathrm{OH}_{2}\right)^{+}$and $\left(\mathrm{R}-\mathrm{NH}_{3}\right)^{+}$may yield positive charges but the overall charge on humus remains negative. Quaternary nitrogen compounds carry positive charges which can alter the behavior of predominantly charged peat colloids ${ }^{[9]}$.

At a certain $\mathrm{pH}$, the soil surface charge could drop to zero rendering a zero zeta potential or what is called the iso-electric point ${ }^{[11]}$. The organic soils surface charge were dropped to zero at $\mathrm{pH} 2-3.5$. Negative surface charge of particles (negative zeta potential) causes electroosmosis to occur from anode to cathode while positive surface charge causes electroosmosis to occur from cathode to anode ${ }^{[11]}$. The electro-osmotic flow can virtually be eliminated at the iso-electric point. When the net charge is zero, organic soil particles in soil water will not repel each other but will tend to aggregate and form larger particles. This in turn will contribute to an increase in soil hydraulic conductivity through the soils. In contrast, negatively charged soil particles repel each other, resulting in dispersion and decrease in soil hydraulic conductivity $^{[12]}$. Figure 3 shows typical values of $\mathrm{pH}$ at iso-electric point of some minerals by comparison with the peat.

Zeta potential and degree of decomposition: Figure 4 indicates the correlation between zeta potential and degree of decomposition. The undecomposed organic soils were more acidic (high fibrous content), as charge in organic soil is strongly $\mathrm{pH}$ dependent, thus the decomposed peat had more negative charge and high zeta potential. However, not only composition and structure of soil humus is complex and incompletely known but also clay and organic fractions strictly affect on electrical properties of organic soils.

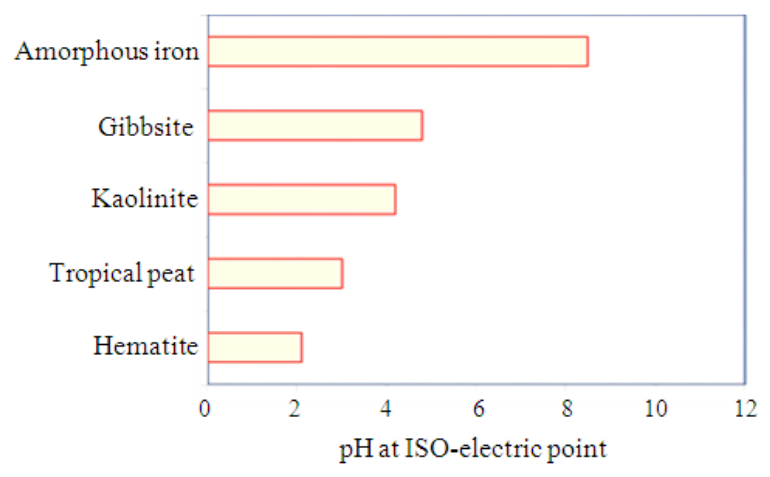

Fig. 3: Iso-electric point of organic soil in comparison with some minerals 
Am. J. Environ. Sci., 5 (3): 310-314, 2009

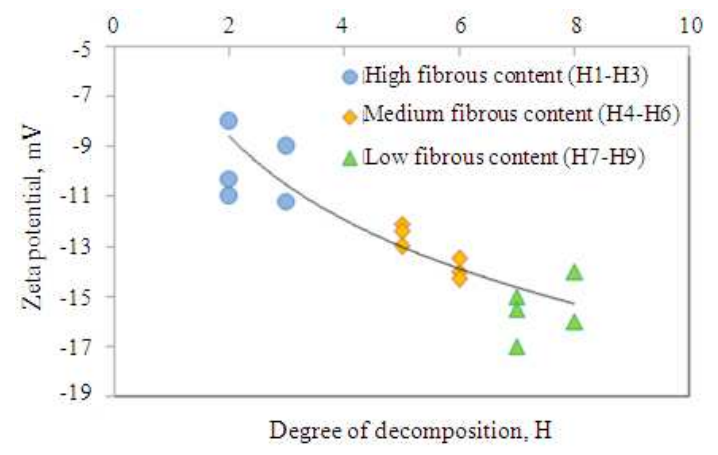

Fig. 4: Zeta potential-degree of decomposition (Van Post scale)

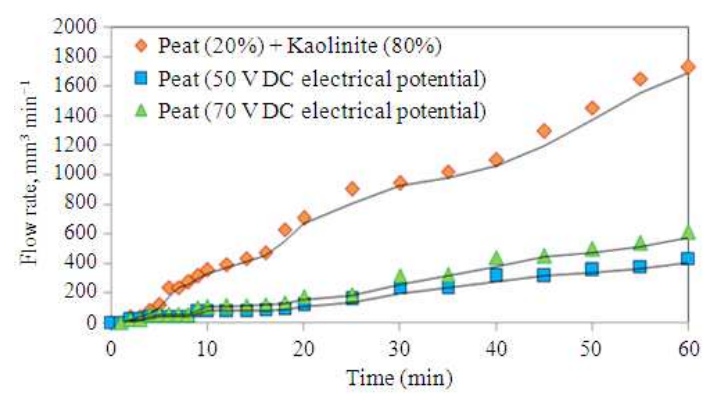

Fig. 5: Electroosmotic flow rates Vs time

Electroosmosis experiments: The cumulative electroosmotic flows in the tested organic soils were toward the cathode Fig. 5. No flow toward the anode was taking place. This is meant no changes in the sign of zeta potential of the soil occurred during the course of experiment ${ }^{[13]}$. Figure 5 also shows the cumulative electroosmotic flows as a function of the time under various applied electric voltages in the tested peat. Increasing the flow rate that resulted from increasing the intensity of electric field can be explained by the Eq. 1, electroosmotic flow rate is proportional to the electric potential. However, further research is required to study the effect of operation time on electroosmotic flows in organic soils.

The final $\mathrm{pH}$ values with experimental condition of $50 \mathrm{~V} \mathrm{DC}$ electrical potential at the cathode, anode and peat were 7.3, 5.2 and 5.9, respectively while the final $\mathrm{pH}$ values with experimental condition of $70 \mathrm{~V}$ DC electrical potential at the cathode, anode and peat were 7.6, 5 and 5.6, respectively. It can be explained by electrolysis of water at the anode and the cathode ${ }^{[14]}$. Electrolysis of water produces oxygen and hydrogen which can be represented by the following equations:

Anode $\quad 2 \mathrm{H}_{2} \mathrm{O}-4 \mathrm{e}^{+} \rightarrow \mathrm{O}_{2}+4 \mathrm{H}^{+}$
Cathode $2 \mathrm{H}_{2} \mathrm{O}+2 \mathrm{e}^{-} \rightarrow \mathrm{H}_{2}+2 \mathrm{OH}^{-}$

While the acid generated at the anode moves through the cathode by ionic electroosmosis and ionic migration the base develops at the cathode. However, since ionic mobility of $\mathrm{H}^{+}$is about 1.76 times that of $\mathrm{OH}^{-}$, as a consequence, the acid controls over the chemistry across the soil and the $\mathrm{pH}$ at the middle of the soil sample decreases ${ }^{[15]}$. It is nothworthy that intensity of electrical potential is proportional with electrolysis of water at the cathode and anode.

\section{CONCLUSION}

Experiments were performed to investigate electroosmotic phenomena on organic soils. Several findings can be drawn specifically for the organic soil and peat used in this study.

- Negative charge in the organic soil is high $\mathrm{pH}$ dependent

- $\quad$ The $\zeta$ for organic soils varies from $-39 \mathrm{mV}$ at $\mathrm{pH}$ 11.5 to almost zero at $\mathrm{pH} 3$

- The high peat degree of decomposition resulted in the higher zeta potential in the organic soil

- The net electroosmotic flows for the organic soil were toward the cathode. This was due to negative sign of zeta potential during EK processing

- Electroosmotic flow rate in organic soil is proportional to the intensity of electric field. The electroosmotic flow rate increase with increasing the intensity of electric field

\section{ACKNOWLEDGMENT}

Financial assistance from the Research Management Center (RMC) of University Putra Malaysia for conducting this study is gratefully acknowledged. We would like to warmly thank Professor Mohd Raihan Taha and Dr. Kamarudin Ahmad for their technical helps and fruitful discussions.

\section{REFERENCES}

1. Mitchell, J.K., 1993. Fundamental of Soil Behavior. 2nd Edn., John and Sons, New York, ISBN: 0471856401, pp: 437.

2. Asadi, A., B.K. Huat and T.A. Mohamed, 2007. Electrokinetic and its applications in geotechnical and environmental engineering. Proceedings of the Congress on World Engineering, Aug. 5-9, Penang, Malaysia, pp: 1-7. http://eng.upm.edu.my/wec2007/congressprogram me.pdf 
3. Huat, B.K., 2004. Organic and Peat Soils Engineering. University Putra Malaysia Press, Serdang.

4. Huat, B.K., S. Maail and T.A. Mohamed, 2005. Effect of chemical admixtures on the engineering properties of tropical peat soils. Am. J. Applied Sci., 2: 1113-1120.

http://www.scipub.org/fulltext/ajas/ajas271113-1120.pdf

5. Duraisamy, Y., B.K. Huat and A.A. Aziz, 2007.

Compressibility behavior of tropical peat reinforced with cement columns. Am. J. Applied Sci., 4: 786-791. http://www.scipub.org/fulltext/ajas/ajas410786-791.pdf

6. Hunter, R.J., 1981. Zeta Potential in Colloid Science. Academic Press, New York, ISBN: 10: 0123619602, pp: 386.

7. Das, M.B., 2008. Advanced Soil Mechanics. 3rd Edn., Routledge, New York, ISBN: 0415420261, pp: 567.

8. Alshawabkeh, A., T. Sheahan and X. Wu, 2004. Coupling of electrochemical and mechanical processes in soils under DC fields. Mech. Mater., 36: 453-465. DOI: 10.1016/S01676636(03)00071-1

9. Fuchsman, C.H., 1986. Peat and Water. Springer, ISBN: 1851660097, pp: 374.

10. Ahluwalia, V.K. and R.K. Parashar, 2006. Organic Chemistry. Vinod Vasishtha, New Delhi.
11. Ahmad, K., K.A. Kassim and M.R. Taha, 2006. Electroosmotic flows and electromigrations during electrokinetic processing of tropical residual soil. Malaysian J. Civil Eng., 18: 74-88.

12. Fang, H.Y. and J.L. Daniels, 2006. Introductory Geotechnical Engineering: An Environmental Perspective. 1st Edn., Taylor and Francis, London and New York, ISBN: 10: 0415304016, pp: 546.

13. Karim, B., F.C. Teddy, D. Andre, B. Yves and D. Patrick, 2005. Role of $\mathrm{pH}$ in electro-osmosis: Experimental study on $\mathrm{NaCl}$-water saturated kaolinite. Transport Porous Media, 61: 93-107. DOI: $10.1007 / \mathrm{s} 11242-004-6798-9$

14. Beddiar, K., T.F. Chong, A. Dupas, Y. Berthaud and P. Dangla, 2005. Role of $\mathrm{pH}$ in electroosmosis: Experimental study on $\mathrm{NaCl}$-water saturated kaolinite. Transport Porous Media, 61:

93-107. http://cat.inist.fr/?aModele $=$ afficheN\&cpsidt $=16747584$

15. Ahmad, K., K.A. Kassim and M.R. Taha, 2005. Influence of electrokinetic processing of tropical soils on the pHs of electrolytes. J. Kejuruteran Awam, 17: 39-48. http://web.utm.my/ipasa/images/stories/MJCE/2005/vol_ 17_no_1/Influence\%20of\%20Electrokinetic\%20Processi ng\%20of\%20Tropical\%20Soils $\% 20$ on $\% 20$ the $\% 20 \mathrm{pHs} \%$ 20 of $\% 20$ the $\% 20$ Electrolytes. pdf 